\title{
The Effect of Age on English Professors' Integration of the New Technologies in Teaching
}

\author{
Hicham Laabidi \\ Part-time Professor at Faculty of Lettres and Human Sciences, Moulay Ismail \\ University, Meknés, Morocco. \\ e-mail: Hicham.laabidi@yahoo.com
}

\begin{abstract}
:
The integration of computer technologies in teaching has become a vital technique to prepare students to face the challenges of the $21^{\text {st }}$ century. Indeed, today's education systems have moved from a focus on information transformation through books, blackboards and chalks to a concentration on information processing via technological instruments, mainly computers, smart phones and tablets. Therefore, teachers are required to adopt these new technologies in their teaching practices. However, it is observed that there are several factors affecting teachers' actual implementation of computer technology in different educational institutions. This paper aims to examine the impact of the age factor on English professors' use of Information and Communication Technology (ICT) in Moroccan higher institutions. Descriptive analysis of means, and standard deviations were used to analyse the collected data. Also, inferential statistics, especially the ANOVA test, were employed to determine the impact of age on ICT adoptions. The findings revealed that there are statistically significant differences in the means of professors' age when integrating ICT in instruction, $F(3,159)=20.455, p<0.05$.
\end{abstract}

Keywords: education systems, information transformation, information processing, technological instruments, ICT 


\section{Introduction}

Information and Communication Technology can be defined as new multimedia technologies, including computer software, CD-ROM, the Internet, mobile phone, television, movie as well as Internet-based Project work, e-mail, chat, blogs, wikis, podcasts, and so on (Andrews, 2000). Lever-Duffy et al. (2005), state that some 'educators may take a narrower view' and predominantly 'confine educational technology (ICTs) primarily to computers, computer peripherals and related software used for teaching and learning' (p. 4-5).

Computer technologies have become a significant characteristic of our daily lives. According to Deaton (1990), “ whether or not we touch a computer, it is almost impossible to escape its daily influence on us; from speedy information transmittal, and receipts, to control of lights and temperature of our workplace" (p.1). Thus, if schools, universities and other educational institutions intend to prepare the new generations for employment, computer technologies must be integrated in teaching and learning practices (Soine, 1996). In this respect, Wilmore (2001) reported that educational institutions which make effective use of ICT in their classrooms, will certainly help learners boost their learning and develop the necessary skills to face life after schooling and the upcoming social and educational shifts.

The use of ICT in the classroom is very essential for providing chances for learners to function appropriately in an information age. Obviously, with the growth of new technologies, the benefits of computers may have increased step by step as well. The centre of attention however, should not be on the computer as an instrument in education, but as a useful learning tool (Bransford et al., 2000; Romeo, 2006). Bransford et al. (2000) state that "what is now known about learning provides important guidelines for uses of technology that can help students and teachers develop the competencies needed for the twenty-first century" (p. 206). Another way of expressing this point is that institutions that do not embody the employment of ICT in schools cannot really claim to get their students ready for life in the twentyfirst century.

Dawes (2001) confirms that technologies have the capacity to assist education across the curriculum and supply chances for useful communication between learners and educators in ways that have not been possible before. That is to say, ICT in education has the ability to be effective in bringing about changes in ways of teaching. Actually, with the advent of the new technologies, learning has become more exciting for learners regardless of their level of education. A lot of studies have revealed that the implementation of ICT in classrooms have come up with many fruitful consequences for both teachers and learners as well. It has increased their willingness to develop their knowledge through these modern tools. Therefore, universities and other educational institutions have realized the value of including computer technologies in instructional processes. Thus, this current paper intends to explore the actual use of the new technologies in Moroccan higher institutions. It aims to answer the following research question: are there any significant differences between professors' use of ICT in terms of their age? 


\section{Literature Review}

\subsection{Computer technologies in Education}

One of the most essential gifts of ICT in the discipline of education is easy access to learning. ICT enhances the flexibility of delivery of education so that students can approach knowledge anytime and from anywhere. It can affect the way learners are taught and how they learn. Indeed, this would get the learners ready for lifelong learning as well as to ameliorate the value of learning. Individuals are recommended to access knowledge by means of ICT to keep pace with the latest advancements (Plomp, Pelgrum\& Law, 2007). ICT can be employed to eliminate communication obstacles such as that of space and time (Lim and Chai, 2004). More precisely, teachers and learners no longer have to depend only on printed books for their educational requirements. With the Internet, a plenty of learning materials can now be accessed from anywhere at anytime of the day. Attwell and Battle (1999) investigate the connection between owning a home computer and school performance, their conclusions propose that learners who have access to a computer at home for educational aims, have advanced scores in reading and math. Becker (2000) discovers that ICT magnifies learner engagement, which guides to an addition amount of time learners to expend working outside class.

Computer technology has the capability to increase teaching and learning opportunities through providing professors as well as learners with more appropriate knowledge and suitable skills (Ouzts \& Palombo, 2004). For this reason, ICT should be incorporated within classrooms. In this context, Miller et al. ( 2000) noted that " the use of technology in education can facilitate learning by providing more relevant learning opportunities, changing the orientation of the classroom from professor to student-centered, preparing students for employment, increasing flexibility of delivery, increasing access, and potentially satisfying demands for efficiency" (p.231). Apparently, higher education institutions are encountering different challenges due to the influence of technological devices on the field of education. Rice and Miller ( 2001) revealed that

Institutions face major challenges in trying to keep pace with technological advances. These challenges include keeping up with the costs of rapidly changing technologies, fostering changes in the learning processes and teaching methods, providing students with the electronic resources they expect, competing with private enterprises investing in distance learning, and training faculty in the use and integration of various technologies. (p. 330).

It is self evident that ICT has been developing very quickly in recent years and opens new directions in the area of education. In other words, the speedy growth in ICT has brought conspicuous and notable changes in the twenty-first century, and influenced the requirements of modern societies. Bransford et al. (2000) confirm that " what is now known about learning provides important guidelines for uses of technology that can help students and teachers develop the competencies needed for the twenty-first century" (p. 206). 
The employment of ICTs in the classroom could foster 'deep' learning and permit teachers to react better to the various requirements of different students (Lau \&Sim, 2008). In other words, ICT is a very significant instrument which, when employed suitably, can cultivate the move to a learner centered environment. Harris (2002) carries out case studies in three primary and three secondary schools, which concentrated on innovative pedagogical practices including ICT. Harries deduces that the advantages of ICT will be obtained "... when confident teachers are willing to explore new opportunities for changing their classroom practices by using ICT". The employment of technology will not only intensify learning conditions but also get next generation ready for coming lives and occupations (Wheeler, 2001).

Actually, the use of computer technology in teaching and learning processes can be very advantageous and profitable for both students and professors. As for students, computer technology can help learners boost their motivation and increase their learning achievements. Also, it can help them become more autonomous and selfreliant in the sense that it enables them define their objectives, assess the outcomes of their learning, and use authentic materials effectively. By authentic materials, I mean the materials that were not originally produced for instructional purpose such the use of electronic magazines, electronic newspapers, songs, movies, etc. As far as professors is concerned, the use of ICT is thought to help teachers change their methodologies of teaching. Instead of sticking to old methods which focus on lecturing, teachers can utilize more modern ways that are highly appreciated by their learners. Moreover, these new innovative technologies could provide countless opportunities to develop professionally.

\subsection{The Effect of Age on ICT Integration}

There are conflicting findings in the literature in terms of the effect of age on ICT integration in education. For instance, Kendel (1995) concluded that the age factor was statistically significant in the sense that younger professors showed more favourable attitudes with regards to the use of ICT for instructional objectives. However, Chio (1992) found that teachers who are old tend to have more positive attitudes towards the implementation of the new technologies in teaching practices. Similarly, Spiegel \& Shohamy (1989) examined the relationship between age and the use of ICT in classrooms. The findings of his study revealed that there was no significant correlation between teachers' age and their attitudes towards computer technologies.

Additionally, Lamboy and Bucker (2003) reported that young professors were more acquainted with computer technological skills than those who were older. Also, Ahadiat (2008) found that teachers who were younger demonstrated a high level of comfort with computers than older ones who found difficulties in employing the new technologies to improve their teaching methodology. Furthermore, Al-Ghonaim (2005) conducted a study at Buraidah College of Technology in Saudi Arabia to investigate professors' integration of ICT in teaching. The results of his study revealed that younger professors had more positive attitudes towards computers than older teachers who less favourable attitudes regarding the use of ICT for educational purposes. 
Dyck \& Smither (1994) found that older instructors possessed more positive attitudes and liking for computer technologies than younger ones. Todman \& Lawrenson (1992) conclude and theorize that

The younger [teachers] became familiar with computers at an early age as an everyday part of their home environment. The older [teachers] lacking this gradual and causal introduction to computers at an early age seem more likely to have been confronted abruptly with pressure to achieve prescribes goals in an unfamiliar and seemingly capricious environment and this is unlikely to be an anxiety reducing experience. (p.69)

\section{Research Methodology}

\subsection{Population}

In this study, approximately 300 teachers were summoned to take part. However, only $195(65 \%)$ full-time and part-time English teachers agreed to respond to the survey. The researcher discarded 32 questionnaires which were incomplete since they had significant parts of the survey instrument missing. Hence, 163 (54, 33\%) answered the questionnaire appropriately. Finally, the resulting sample size employed in this study was a total of 163 teachers working in various Moroccan higher institutions.

\subsection{Instruments}

The researcher used a questionnaire entitled "Use of Computer Technology". It was adapted from the instrument designed by O'Dwyer et al.(2004). The instrument was originally developed to assess the integration of computer technology by middle and high school teachers in the U.S. It contained four major aspects regarding teachers' use of ICT in their teaching. These aspects were: Teachers' Use of ICT tools for Delivering Instruction (TUTDI), Teachers' Use of ICT for Class Preparation (TUTCP), Teachers and Students' Use of ICT to Create Products (TSUTCP), and Teachers' Use of ICT during Class Time (TUTCT). The items included in the instrument were rated on a five-point scale $(1=$ never, $2=$ once or twice a year, $3=$ several times a year, $4=$ several times a month, and $5=$ several times a week). Higher scores on each facet suggest that teachers employ ICT devices more often in their teaching. It is worth-stating that the questionnaire was slightly modified by removing and adding other statements related to the use of computer technology in classrooms. It was originally composed of twenty items. However, in this paper, it consisted of twelve items that were ranked on a five-point Likert scale ranging from never, once or twice a year, few times a year, few times a month and several times a month. O'Dwyer et al. (2004) tested the reliability of the instrument they employed to collect the necessary data. They reported that the coefficient alpha reliabilities were .74 for TUTCP and .85 for TUTCT. As far as validity, it was established by having experienced professors thoughtfully scrutinize the material this instrument was to cover. 


\subsection{Data Analysis Procedures}

Both descriptive and inferential statistical analyses were used to answer the research question: are there statistically differences in professors' use of computer technology based on age? Inferential statistics, mainly the Analysis of Variance (ANOVA) to answer this research question. ANOVA was employed to conclude whether there were statistically significant differences among the means of the groups. The dependent variable was professors' use of computer technology and the independent variable was age.

\section{Findings and Discussion}

\subsection{Demographic Data of the Participants}

Responses on the first section of the survey questionnaire provided demographic data about the professors who participated in this study. The data describing the demographic characteristics were computed and analyzed using descriptive statistics such as frequencies and percentages. The examined demographic information incorporated age and university of affiliation.

\subsubsection{Age of the Participants}

The first demographic variable examined on the questionnaire was age. The age of the participants in this study ranged from less than 30 to greater than 51. This information is demonstrated in figure 1. About half of the participants $(46.6 \%, \mathrm{n}=$ 76) were 51 years old or older. Also, almost one third of the respondents $(28.2 \%$; $=46)$ were within the 41-50 age range, $16.6 \%(n=27)$ were between 30-40 age range, and only $8.6 \%(\mathrm{n}=14)$ were less than 30 years old.

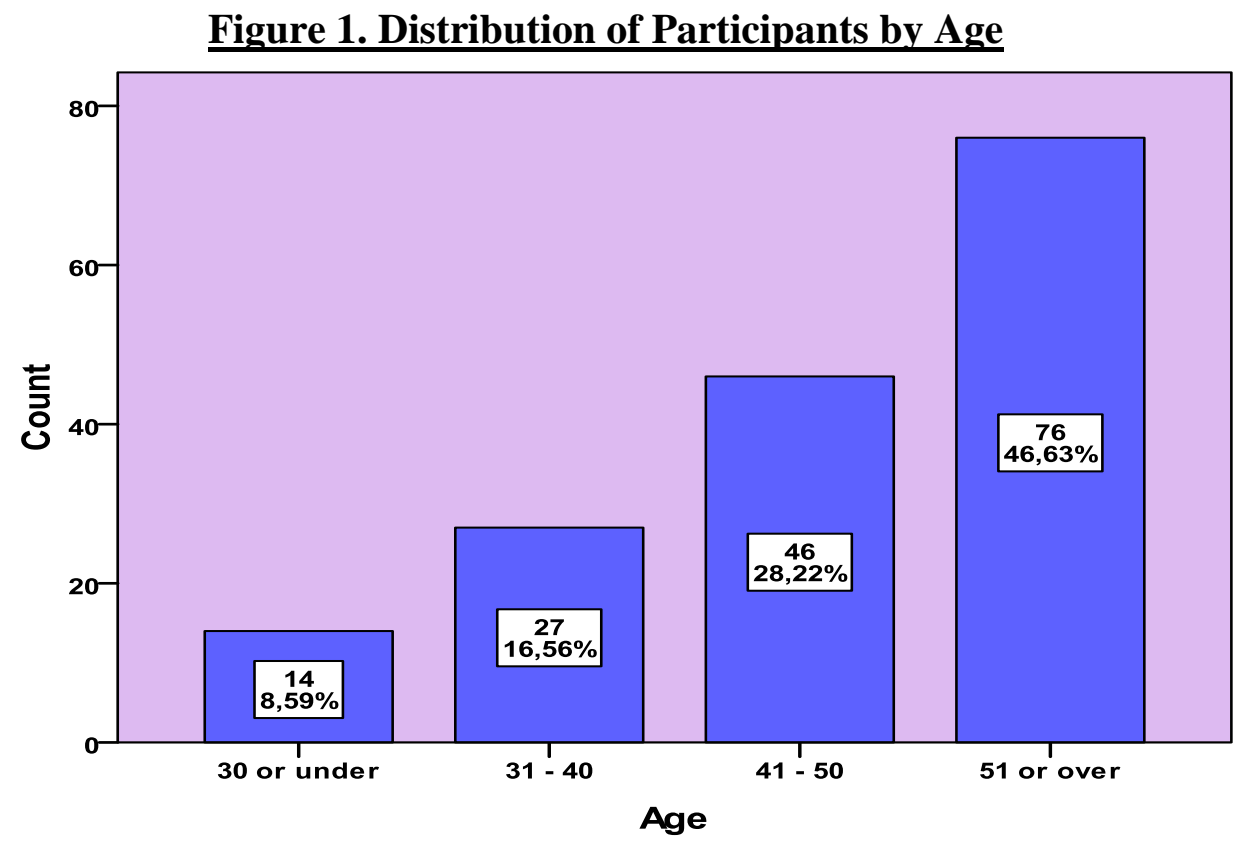




\subsubsection{University of Affiliation of the Participants}

As illustrated in Figure 2, the professors participating in this study were from thirteen different Moroccan universities. The highest percentage of the respondents $21.5 \%(\mathrm{n}=35)$ taught English language at Moulay Ismail University followed by Sidi Mohammed BenAbdellah university, $14.1 \%(\mathrm{n}=23)$. Of the 163 participants, $11.7 \%(\mathrm{n}=19)$ taught at Mohammed V. The data showed that the representation of Mohammed I was somewhat less, $4.3 \%(\mathrm{n}=7)$, equal with both Ibnou Zohr and Soultane Solimane universities. Furthermore, about $10 \%$ of the professors taught at Hassan II university. Actually, a small sample of the respondents (1.23) taught at AL Akhawayne University which is a private institution.

\section{Figure 2. Distribution of Participants by University of Affiliation.}
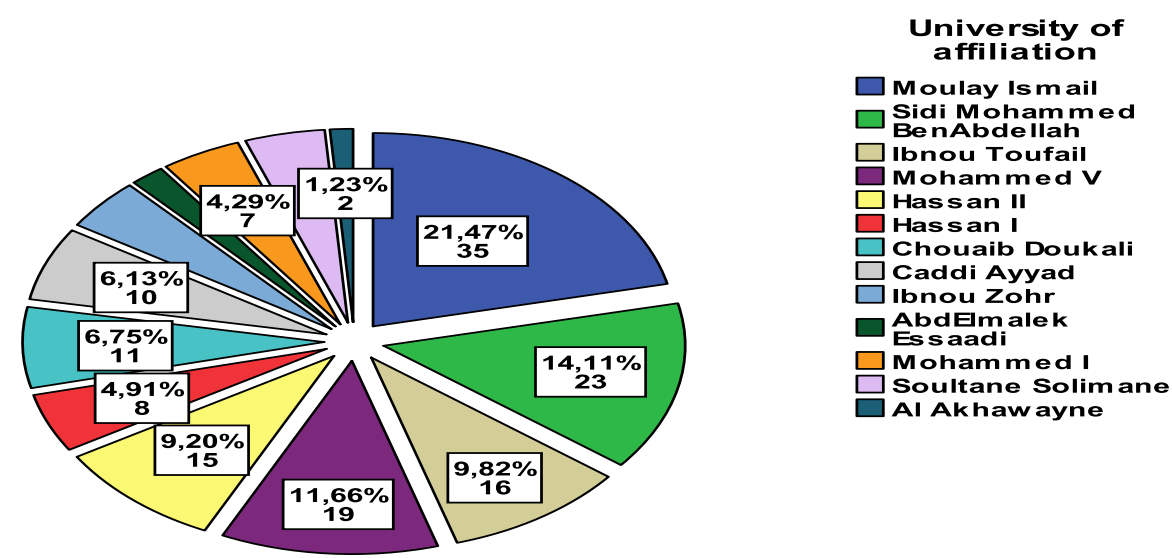

\subsection{Findings Related to the Research Questions}

Below is the presentation of the findings related to the research questions.

Table 1. Descriptive Statistics of Professors' Age

\begin{tabular}{|c|c|c|c|c|}
\hline Age & N & Mean & Std. Deviation & Std. Error \\
\hline 30 or under & 14 & 2,64 &, 58 &, 15 \\
$31-40$ & 27 & 2,41 &, 64 &, 12 \\
$41-50$ & 46 & 1,97 &, 80 &, 11 \\
51 or over & 76 & 1,20 & 1,02 &, 11 \\
Total & 163 & 1,74 & 1,02 &, 08 \\
\hline
\end{tabular}

According to Table 1, the means of the four age groups on professors' use of ICT differ from one another. In fact, participants aged 30 or under obtained the highest mean score $(\mathrm{M}=2.64, \mathrm{SD}=0.58)$, followed by respondents aged between 31 and 40 with a mean score of 2.41 ( $\mathrm{SD}=0.64)$. Also, participants aged between 41 and 50 
scored a mean of $1.20(\mathrm{SD}=0.80)$. Actually, the oldest participants aged 51 or over recorded the lowest mean score $(\mathrm{M}=1.20, \mathrm{SD}=1.02)$. These results are wellrepresented in the following Figure.

Figure 3. Means Plot for age and ICT use in teaching

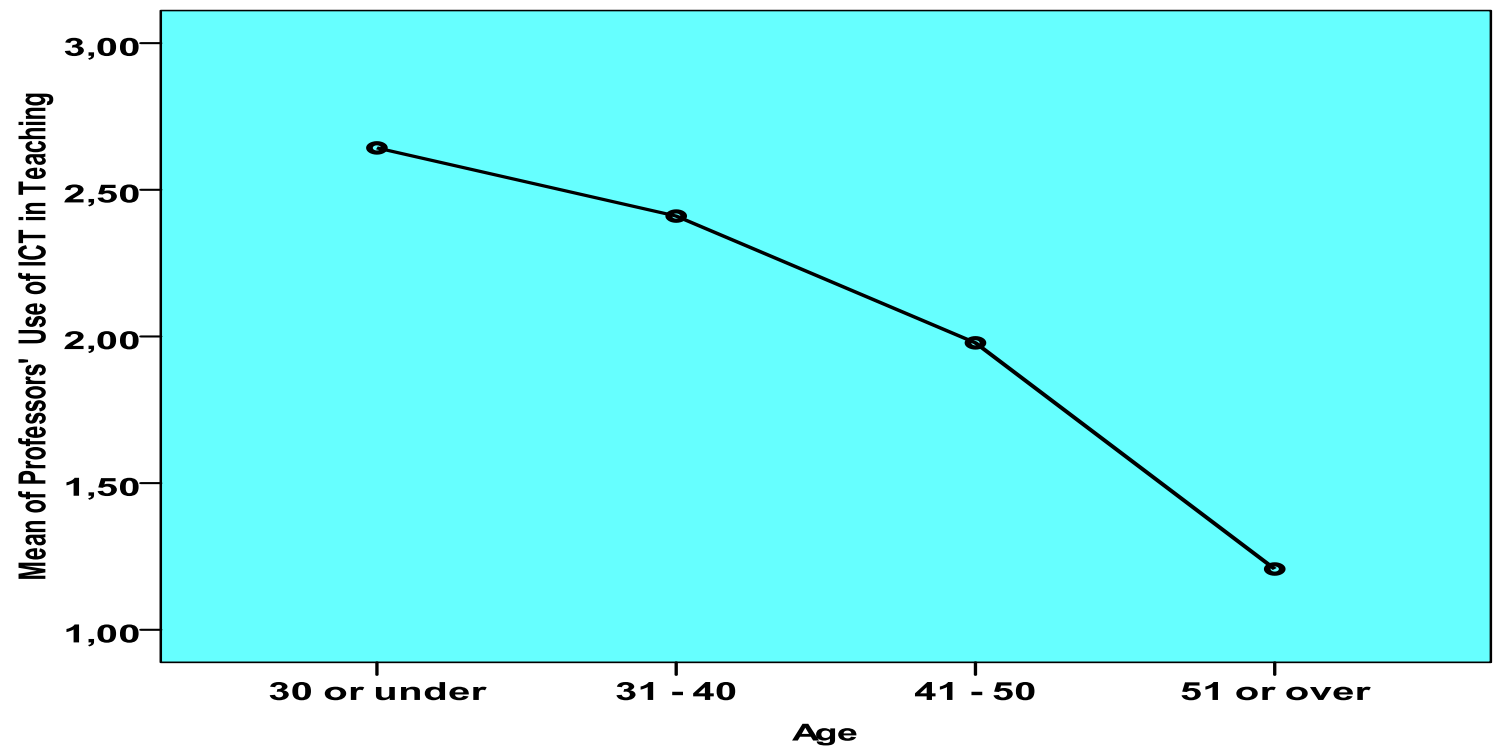

The means plot for age and computer technology implementation in teaching revealed that the oldest professors are less expected to integrate technological instruments in their classrooms. Therefore, there are differences between professors' use of ICT based on age as the ANOVA result demonstrates in the following table.

Table 2. One-way between groups ANOVA for age and ICT use in teaching.

\begin{tabular}{|c|c|c|c|c|c|}
\hline ANOVA & Sum of Squares & Df & Mean Square & F & Sig. \\
\hline Between Groups & 47,724 & 3 & 15,908 & 20,455 &, 000 \\
Within Groups & 123,657 & 159 &, 778 & & \\
Total & 171,381 & 162 & & & \\
\hline
\end{tabular}

The findings of the one-way ANOVA test revealed that there are statistically significant differences in the means of professors' age when integrating ICT in instruction, $F(3,159)=20.455, \mathrm{p}<0.05$. Consequently, since the $\mathrm{p}$ value $(\mathrm{p}=0.000)$ was smaller than the significant level set at 0.05 (2-tailed), the null hypothesis 
indicating that there were no significant differences between the two variables was rejected. The effect size, calculated utilizing eta squared, was 0.27 . To interpret the strength of Eta squared values, the following guidelines were used: $0.01=$ small effect, $0.06=$ moderate effect, $0.14=$ large effect (Cohen, 1988). The magnitude of the differences in the means was large (eta squared $=0.27$ ). This means that $27 \%$ of the variance in professors' use of ICT in the classroom is explained by age. In other words, age is not the only factors influencing professors' integration of computer technology in their teaching practices.

In fact, because the one-way ANOVA test showed that differences exist among the various age groups, a Scheffé Post Hoc test was utilized to identify which group is significantly different from other groups. The results are demonstrated in the following table.

Table 4. Post Hoc Test ( Scheffe) for age and ICT use in teaching

\begin{tabular}{|c|c|c|c|c|c|c|}
\hline \multirow[b]{2}{*}{ (I) Age } & \multirow[b]{2}{*}{ (J) Age } & \multirow{2}{*}{$\begin{array}{c}\text { Mean } \\
\text { Difference (I-J) }\end{array}$} & \multirow[b]{2}{*}{ Std. Error } & \multirow[b]{2}{*}{ Sig. } & \multicolumn{2}{|c|}{$95 \%$ Confidence Interval } \\
\hline & & & & & Lower Bound & Upper Bound \\
\hline \multirow[t]{3}{*}{30 or under } & $31-40$ & ,23236 & 29044 & ,887 &,- 5883 & 1,0531 \\
\hline & $41-50$ & ,66460 & ,26918 &, 112 &,- 0960 & 1,4252 \\
\hline & 51 or over & $1,43562^{*}$ & ,25648 &, 000 & ,7109 & 2,1604 \\
\hline \multirow[t]{3}{*}{$31-40$} & 30 or under &,- 23236 & ,29044 &, 887 & $-1,0531$ &, 5883 \\
\hline & $41-50$ & ,43223 & ,21380 &, 256 &,- 1719 & 1,0364 \\
\hline & 51 or over & $1,20326^{*}$ & , 19758 &, 000 &, 6450 & 1,7615 \\
\hline \multirow[t]{3}{*}{$41-50$} & 30 or under &,- 66460 & ,26918 &, 112 & $-1,4252$ &, 0960 \\
\hline & $31-40$ &,- 43223 & ,21380 & ,256 & $-1,0364$ &, 1719 \\
\hline & 51 or over &, $77102^{*}$ &, 16474 &, 000 & ,3055 & 1,2365 \\
\hline \multirow[t]{3}{*}{51 or over } & 30 or under & $-1,43562^{*}$ & ,25648 &, 000 & $-2,1604$ &,- 7109 \\
\hline & $31-40$ & $-1,20326^{*}$ & , 19758 &, 000 & $-1,7615$ &,- 6450 \\
\hline & $41-50$ &,$- 77102^{*}$ & , 16474 &, 000 & $-1,2365$ &,- 3055 \\
\hline
\end{tabular}

*. The mean difference is significant at the 0.05 level.

According to Table, there are only small differences between professors' integration of computer technologies in teaching with respect to the factor of age. Only the 
group of respondents aged 51 or over is statistically different from the remaining groups. This suggests that participants aged 51 or more use ICT less frequently than the other respondents.

\section{Conclusions}

Information and Communication Technologies have become significant instructional instruments in higher educational institutions in different parts of the world including Morocco. However, it is apparent that the effective use of these new devices relies on the existence of appropriate conditions. In other words, successful implementation of ICT in teaching processes cannot be achieved without erasing the barriers that hinder its effective use in classrooms.

According to the findings of this paper, there are significant differences between professors' integration of the new technologies based on age. In fact, young teachers tend to make more use of ICT for instructional purposes than older professors. Therefore, it is possible to conclude that age might have some impacts on professors' decision to incorporate modern technologies in their classrooms. It is worth-stating that there are more other variables that affect professors' use of Information and Communication Technology in teaching. These factors include teachers' gender and attitudes towards different technological gadgets.

Based on the results of this study, the following recommendations can be suggested. Up-to-date training programs should be provided on a continuous manner for professors to help them understand how to make effective use of ICT in their classrooms. Moreover, the training offered to the professors should not only focus on developing professors' computer skills, it should also concentrate on showing them how to integrate these technologies in their teaching performance. Furthermore, appropriate technological infrastructure, enough equipments, up-todate software, access to computers and to the internet, and financial support should be provided in all educational institutions to guarantee the successful adoption of the new technologies in the classrooms. Also, it is strongly recommended that administrators need to provide programs that aim at changing those negative attitudes towards the use of new modern technological tools in teaching. Finally, policy makers need to become better informed about the various factors that hinder the effective and successful implementation of Information and Communication Technologies within educational institutions including universities.

\section{References}

Ahadiat, N. (2008). Technologies used in accounting education: A study of frequency of use among faculty. Journal of Education for Business, 10, 123133.

Al-Ghonaim, H. S. (2005). Attitudes, barriers, and incentives of Saudi college instructors and administrators of online instruction. (Doctoral dissertation, University of Kansas, 2005). ProQuest Digital Dissertations, UMI No. AAT 3185123.

Attwell, P; Battle, J. (1999)."Home Computers and School Performance" .The Information Society. No. (15), Pp. 1-10. 
Andrews, R. (2000). Learning, Literacy and ICT: What's the connection? English in Education, 34 (3), 3-18.

Becker, H. J. (2000). "Pedagogical Motivations for Student Computer Use that Leads to Student Engagement". Education Technology. Vol. 40, No. 5, Pp; 517.

Bransford, J., Brown, A. L., \& Cocking, R. R. (Eds). (2000). How people learn: Brain, mind, experience, and school (2nd ed.). Washington, D.C: National Academy Press.

Chio, Y. K. (1992). Attitudes toward and knowledge of microcomputers used for instruction among commercial high school teachers in Korea. Unpublished EDD dissertation. University of Georgia. AAT 9316322.

Dawes, L. (2001). What stops teachers using new technology. In M. Leask (Ed.), Issues in Teaching using ICT (pp. 61-79).London: Routledge.

Deaton, M. P. (1990). Computer integration in the primary grades. (ERIC Document Reproduction Services No. ED 337 137).

Dyck, J.L., \& Janan, S.(1994). Age differences in computer anxiety: The role of computer experience, gender, and education. Journal of Educational computing research, 10,239-248.

Harris, S. (2002). Innovative pedagogical practices using ICT in schools in England.Journal of Computer Assisted Learning, No. 18, Pp;449-458.

Kendel, M. M. (1995). Computer attitudes and use of public and secondary school teachers in Kentucky. Unpublished Ed D dissertation. University of Kentucky. AAT 9523940.

Lamboy, C. L., \& Bucker, A. J. (2003). An investigation of faculty technology skills in a Puerto Rican university. The Quarterly Review of Distance Education, 4(2), 143152.

Lau BT and Sim CH. (2008). Exploring the extent of ICT adoption among secondary school teachers in Malaysia. International Journal of Computing and IT Research, Vol. 2 (2) 19-36

Lever-Duffy, J. McDonald, J. B. and Mizell A. P. (2005) Teaching and learning with technology. 2nd ed. San Francisco: Pearson.

Lim, C. P. \& Chai, C.S. (2004), An activity-theoretical approach to research of ICT integration in Singapore schools: Orienting activities and learner autonomy', Computers \& Education Vol. 43, No. (3), Pp; 215--236.

Miller, J. W., Martineau, L. P., \& Clark, R. C. (2000). Technology infusion and higher education: Changing teaching and learning. Innovative Higher Education, 24(3), 227- 241.

O'Dwyer, L. M., Russell, M., \& Bebell, D. (2004). Identifying teacher, school and district characteristics associated with elementary teachers' use of technology: A multilevel perspective. Education Policy Analysis Archives, 12(48), http://epaa.asu.edu/epaa/v12n48

Ouzts, D. T., \& Palombo, M. J. (2004). Technology in higher education: A study of perceptions of college professors. Tech Trends, 48(5), 19-25. 
Plomp, T.; Pelgrum, W. J. \& Law, N. (2007), 'SITES2006-International comparative survey of pedagogical practices and ICT in education', Education and Information Technologies Vol.12, No. (2), Pp; 83- 92.

Rice, M., \& Miller, M. T. (2001). Faculty involvement in planning for the use and integration of instructional and administrative technologies. Journal of Research on Computing in Education, 33(3), 328-336.

Romeo, G. (2006). Engage, empower, enable: Developing a shared vision for technology in education. In D. Hung \& M. S. Khine (Eds), Engaged learning with emerging technologies ( $\mathrm{pp}$. 149-175). Dordrecht, the Netherlands: Springer.

Seliger, H., \& Shohamy, E. (1989). Second language research methods. Cambridge: Cambridge University Press.

Soine, R. M. (1996). Require students to gain computer skills - now what? Teaching for Success, 8(2), 7.

Todman,J.,\& lawrenson,H.(1992). Computer anxiety in primary schoolchildren and university students. British Educational Research Journal, 18(1), 63-72.

Wheeler, S. (2001). Information and communication technologies and the changing role of the teacher. Journal of Educational Media, Vol. 26, No.(1), Pp;7-17.

Wilmore, D. (2001). Establishing a community of learners: the use of information technology (IT) as an active learning tool in rural primary or elementary schools. Educational Technology \& Society, 4(3), 11-20. 